\title{
The Wildlife of Ethiopia
}

\author{
By John Blower
}

Still relatively rich in the larger African mammals despite the destruction of recent years, Ethiopia is tackling wildlife conservation problems in earnest. In 1965 the Imperial Government set up a Wildlife Conservation Department, and appointed John Blower as Senior Game Warden and adviser on wildlife conservation. Several national parks are now scheduled, and it is hoped that the first, the Awash National Park, will soon be officially opened by the Emperor. This is in the very rich Awash Valley to the east of Addis Ababa, where a wide range of animals includes greater and lesser kudu, beisa oryx, gerenuk, klipspringer, leopard, lion, cheetah, a few Swayne's hartebeest, now on the verge of extinction, and many birds. Two other proposed national parks, in the Simien Mountains and the Bale Mountains, will protect Ethiopia's four endemic mammals, the rare walia ibex, the Simien fox, gelada baboon and the mountain nyala. A map of Ethiopia is on pages 284-5

$\mathbf{E}$ THIOPIA, 450,000 square miles in area and with a population of 22 million, stands like some great terrestrial island athwart the Horn of Africa. Roughly the shape of an equilateral triangle, with its northern apex touching the 18 th parallel, it is bounded to the east by a 500 -mile stretch of the Red Sea coast and by the borders of French Somaliland and the Somali Republic; to the south - only some $4^{\circ}$ north of the equator by the sun-scorched wilderness of Kenya's Northern Frontier Province; and along the whole of its long western border by the vast plains and swamps of the Sudan.

The central and western part of the country consists of a well-watered but deeply dissected plateau with an altitude varying between 6,000 and 10,000 feet, but rising at its highest (Ras Dashan in the Simien Mountains) to over 15,000 feet. By contrast, arid lowlands ranging from open grassy steppe and thorn scrub to sterile desert, in places reaching 400 feet below sea level, extend from the foot of the towering escarpments which guard the approaches to the high plateau eastwards towards the Red Sea and the Gulf of Aden.

Bisecting the highlands like a great sword-cut, the Rift Valley - a series of lakes strewn along its broad floor - runs diagonally from Lake Rudolf north-eastwards for some 800 miles to the Danakil desert and the distant Red Sea. Further north the Blue Nile, Takkaze and other rivers draining westward into the Nile basin have cut their own great trench-like canyons - often a mile deep and five to ten miles across - through the broken mountainous landscape. Other major rivers include the Omo and Awash, both of which rise in the central highlands of Shoa, near Addis Ababa; the former flowing south-west through deep tortuous gorges and across the broad alluvial plains of the lower Omo Valley to empty into Lake Rudolf, and the Awash north-eastwards, down the Rift Valley, eventually to lose itself among the deserts, extinct volcanoes and blackened lava flows of Danakil. 

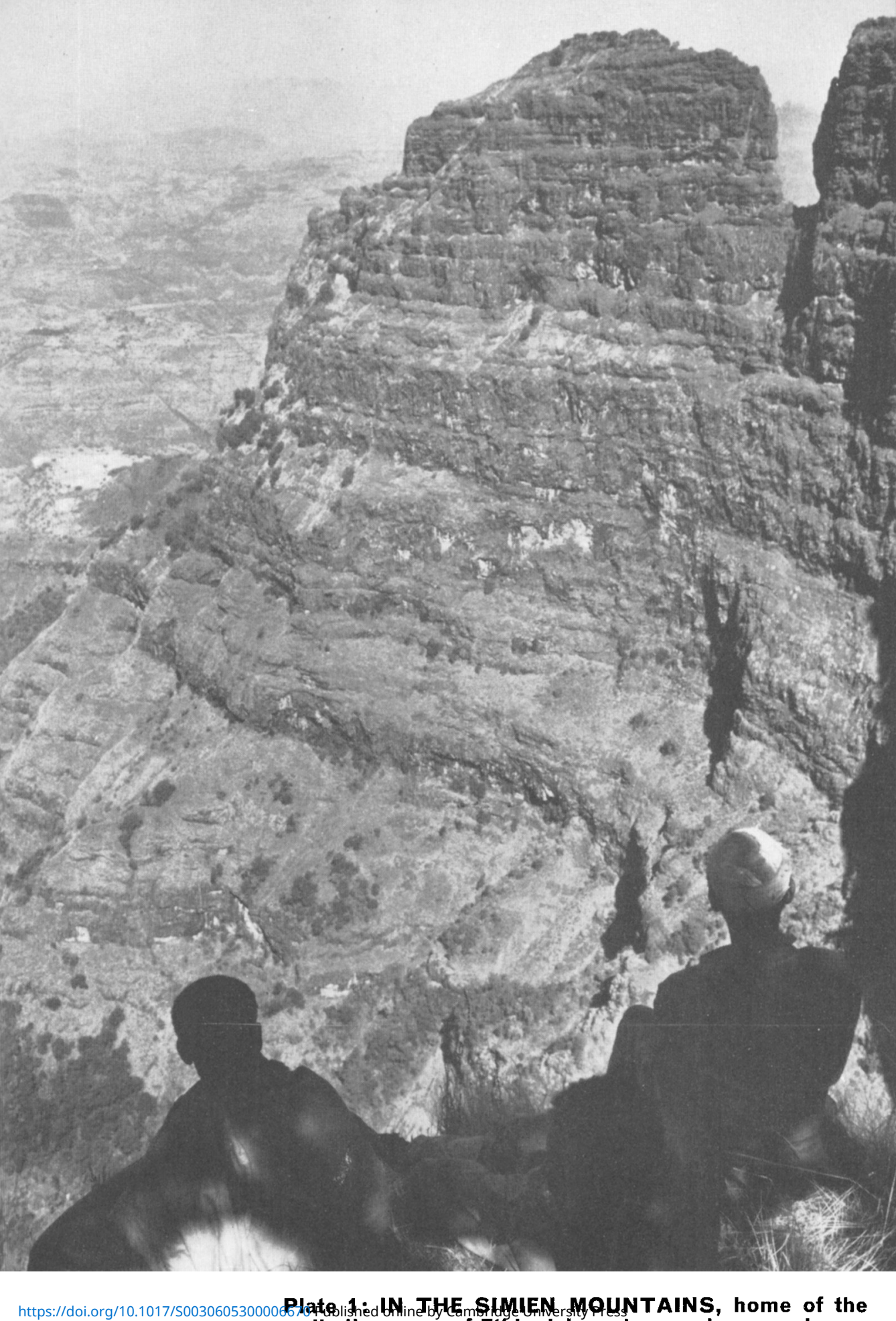



Apart from these perennial rivers and the Rift Valley lakes already mentioned, Ethiopia's largest expanse of inland water is Lake Tana, with an area of some 1,300 square miles, near the ancient Imperial capital of Gondar, in the north-west. A shallow lake scattered with small islands, Tana serves as a natural reservoir for the Great Abbai or Blue Nile, which flows out over the spectacular Tisissat Falls, and thence cuts its way south and west through immense gorges towards the Sudan and its eventual confluence with the White Nile at Khartoum.

As the largest mountain block in Africa, bounded to east and south by deserts beyond which lie the Red Sea and Indian Ocean, and to the west by the vast plains and swamps of the Nile basin, the Ethiopian plateau has its own well-defined climatic characteristics and also exerts a marked influence on the whole surrounding region. Rainfall on the plateau itself averages $40-80$ inches and is mostly concentrated between June and September, while temperatures in Addis Ababa range from $37^{\circ}$ to $79^{\circ} \mathrm{F}$, though at higher altitudes they frequently drop below freezing point at night. In Danakil and along the Red Sea littoral rainfall varies from nil to seven inches (Massawa) and shade temperatures may sometimes reach $115^{\circ} \mathrm{F}$.

With such unusual differentiation in altitude and exceptionally wide climatic variations it is hardly surprising that Ethiopia presents a range of biological environments unparalleled elsewhere in Africa. Occurring in a series of more or less clearly defined altitude-related zones from the arid desert of the coastal belt, with its very sparse xerophytic vegetation, through steppe, savanna woodland, evergreen thicket and scrub to highland evergreen forest, and finally Afro-alpine formations above about 10,000 feet, they support an unusual variety of biotic communities ranging from those typical of tropical Africa to those with closer affinities to the Palaearctic region.

The magnificent forests which must once have extended over much of the plateau have now been almost wholly obliterated through the improvident and excessively destructive habits of the people - their place taken by the ubiquitous plantations of eucalyptus first introduced by the Emperor Menelik in 1895, though occasional fast disappearing remnant patches of Juniperus (pencil cedar), Podocarpus, Olea, Hagenia and other indigenous species give some indication of the original character of the natural forest covering. The only extensive areas of forest still surviving are in the south-west, particularly in Kaffa Province, where there remain great virgin tracts of mountain rain-forest, preserved by their relative inaccessibility and the sparseness of the human population, and as yet botanically and zoologically largely unexplored.

Like the forests, the wildlife of much of Ethiopia has been decimated, particularly following the large-scale introduction of firearms since the beginning of the last century. Ethiopians have always been a warlike people and hunting big game has been regarded as a manly pursuit in which a warrior could prove his martial prowess in the absence of human antagonists, and thereby win the admiration of his fellows, and more especially that of the opposite sex. Until comparatively recently the slaying 
of an elephant was accounted equivalent to killing 40 men; a buffalo, rhinoceros or lion to five men, and so on. Successful hunters were entitled to wear gold earrings and other marks of distinction, and were accorded considerable respect and prestige in the community, while the financial returns from ivory, rhinoceros horn and other trophies were an added incentive. It is not therefore surprising that the consequent uncontrolled slaughter of game, combined with the widespread destruction of habitat and the increasing pressure of agricultural settlement, should have led to the virtual extermination of all larger forms of wildlife throughout the comparatively densely populated highland areas.

It is true that such species as greater kudu are still fairly numerous and widely distributed among the rocky, scrub-covered foothills, and also that bushbuck, waterbuck, warthog, reedbuck, klipspringer, duiker - and occasionally leopard and giant forest hog - may still be found in some of the remoter and more sparsely populated regions. But in general the only highland areas where larger forms of wildlife survive in significant numbers today are the Bale and Arussi mountains, to the south-east of the Rift Valley, the Simien Mountains near Gondar, in the north-west, and in the Red Sea Hills of Northern Eritrea.

Bale and Arussi, south of Addis Ababa, and also a part of the neighbouring Chercher Mountains, include the whole known range of the mountain nyala (Tragelaphus buxtoni). This magnificent kudu-like antelope, with a total estimated population of $4,000-5,000$ (Brown 1967), is endemic to Ethiopia and confined to the high moorlands between 10,000 and 13,000 feet, where it dwells among the tree heath (Erica arborea) and St. John's wort (Hypericum lanceolatum), occasionally wandering down into the forest on the lowerslopes. Other species which share this wild moorland habitat are the Simien fox Simenia simensis, Menelik's bushbuck, klipspringer, hyrax and a rich variety of bird-life including the lammergeier, Verreaux's eagle, augur buzzard, wattled crane and the blue-winged goose.

Simien in the north is the highest mountain massif in Ethiopia, and with its fantastic northern precipice wall, 20 miles in length and rising sheer for $4,000-5,000$ feet, offers perhaps the most spectacular scenery in Africa. These breathtaking precipices with their narrow grassy ledges and hidden caves are the home of the walia ibex (Capre walie), of which only some 200-300 are now believed to exist. The walia, like the gelada baboon (Theropithecus gelada) and Simien fox which share its habitat, is another endemic Ethiopian species. Both Simien and a part of the Bale Mountains are scheduled for development as national parks under Ethiopia's newly introduced wildlife conservation programme. An expatriate warden is already in Simien, together with a Swiss zoologist, Dr Bernhard Nievergelt, who is carrying out a 12-month study of the walia ibex financed jointly by the Swiss National Fund, the Swiss Foundation for Alpine Research and the World Wildlife Fund.

Some 250 miles north of the Simien Mountains the Nubian ibex (Capra nubiana) reaches the southern extremity of its range in Africa in the Red Sea Hills of Northern Eritrea, a chain of barren sun-scorched peaks and scrub-strewn valleys which extend northwards parallel with the coast to 
the latitude of Saukin on the Sudan Red Sea coast. However, though the status of this species in Eritrea is not yet accurately known, it is certainly more numerous than the walia ibex, while its overall range extends to the eastern shore of the Red Sea, in the Arabian peninsula, in addition to Eritrea and the Sudan. Other species found in northern Eritrea include the dorcas gazelle (Gazella dorcas isabella and G. d. littoralis), probably the Nubian wild ass, and possibly the Barbary sheep.

Apart from these isolated highland areas of special interest as the habitat of certain endemic or relatively rare species, the only other areas where wildlife still survives in significant number and variety are in the peripheral lowlands. These are divided into several separate and ecologically dissimilar regions, though inevitably the boundaries between them are generally indistinct.

Of these lowland areas one of the more important to the conservationist, since its still relatively abundant fauna is characteristic of and in some respects unique to the Horn of Africa, is the vast triangle of desert and steppe lying to the west of the southern end of the Red Sea. Extending between approximately $9^{\circ} 30^{\prime}$ and $14^{\circ} 30^{\prime} \mathrm{N}$, it is bounded to the west by the Ethiopian escarpment, and contains within it a variety of strangely contrasting topography from the bizarre brightly-coloured mineral deposits of the Danakil Depression in the north, across volcano-dotted deserts to the fertile valley of the Awash in the south.

\section{Home of the Somali Wild Ass}

In this region, generally known as Danakil, from the name of the wild nomadic pastoralists who inhabit it, the commonest and most widely distributed of the larger mammals are beisa oryx and Soemmering's gazelle, while the rarest is the Somali wild ass (Equus asinus somalicus). This species is now reported to be nearing extinction in Somalia (Funaioli and Simonetta, 1966) and only survives in any significant numbers in central Danakil, where the writer recently counted 83 in the neighbourhood of Sardo $\left(11^{\circ} 58^{\prime} \mathrm{N}, 41^{\circ} 18^{\prime} \mathrm{E}\right)$ near the main Assab road. The range of the Somali wild ass in Ethiopia extends from the Danakil Depression southwards to Lake Hertale, east of Addis Ababa $\left(9^{\circ} 55^{\prime} \mathrm{N}, 40^{\circ} 24^{\prime} \mathrm{E}\right)$, but it is doubtful if the total population exceeds a few hundred, and the species is certainly in urgent need of both effective protection and scientific investigation of its status and ecological requirements.

Of this whole area the richest part in both number and variety of wildlife is the Awash Valley, and it is for this reason that it has been selected as the location for Ethiopia's first national park (and also for an adjoining and much larger game reserve). Here, in addition to numerous oryx and Soemmering's gazelle, are Grévy's zebra, greater and lesser kudu, gerenuk, defassa waterbuck, klipspringer, Chanler's reedbuck and dikdik (Madoqua sp). Other ungulates include a handful of Swayne's hartebeest (Alcelaphus buselaphus swaynei), a species which only 70 years ago was to be seen in tens of thousands in eastern Ethiopia and Somalia (Swayne, 1900) but which is now on the verge of extinction. Among the carnivora are leopard, lion, cheetah, spotted and striped hyaena, aardwolf, caracal, jackal and bat-eared fox. 
Further south, beyond Harar and the Chercher Mountains, lies the Webbe Shebeli basin and the featureless steppe and thornscrub of the Ogaden, extending eastwards in a great wedge bounded to north and south by the borders of Somalia. Its once rich game stocks have, unfortunately, been continually harried in recent years by the military forces operating there, until now there remain but a few scattered remnants of the Ogaden's former great herds of plains game, while even they are doomed soon to disappear unless firm measures are taken to curb the activities of the trigger-happy soldiery. Apart from oryx and Soemmering's gazelle, gerenuk and lesser kudu are still fairly widely distributed, while Speke's gazelle (Gazella spekei) and dibatag (Ammodorcas clarkei) occur near the Somalia border. The only surviving elephant population in eastern Ethiopia - probably numbering not much more than a hundred - continues to maintain a precarious existence in the upper reaches of the Webbe Shebeli and Fafan river systems, to the east of Harar. Lion are still relatively common, while other species include warthog, dikdik (Madoqua and Rhynchotragus spp), greater kudu, waterbuck (Kobus ellipsiprymnus not $K$. defassa as elsewhere in Ethiopia), greater kudu, klipspringer, leopard, cheetah and caracal. Giraffe and zebra were to be found in the southern Ogaden until comparatively recently though their continued survival in the area is doubtful.

Travelling westwards through Borana, parallel with the Kenya border, the fauna becomes progressively more characteristic of East Africa proper, as distinct from that of the Horn of Africa. While the range of the Soemmering gazelle extends as far west as the Dawa Parma River, beyond which it is replaced by the Grant's gazelle, and that of the oryx as far as the west bank of the Omo River, there are also buffalo, elephant, a very few rhinoceros, and - further west - tiang, both Grévy's and Burchell's zebra, reticulated giraffe, Swayne's and Lelwel hartebeest, and reportedly a hybrid between these two races (Neumann's hartebeest?). However, here again the game has suffered much at the hands of the heavily armed local populace and military, and its numbers have been seriously depleted in recent years.

\section{Game Reserve In the Omo Valley}

The lower Omo Valley is relatively inaccessible and sparsely populated, while it has been happily free from the depredations of military forces. Consequently, though by no means immune from poaching, it remains one of the richest game areas in Ethiopia, while the Omo river itself is of importance as a major physical barrier limiting the distribution of certain species. Thus, while Grévy's zebra and gerenuk are found to the east, they do not extend westwards of the river, while conversely eland and Mongalla gazelle ( $G$. thomsoni albonotatus) occur on the west bank, but not on the east. The largest concentrations of game are to the west of the river, where a game reserve is being established which, it is hoped, may eventually be upgraded to national park status. Here the most numerous of the larger ungulates is the eland, which may often be seen in herds numbering several hundred, while among other plains game are tiang, oryx, Burchell's zebra, Lelwel hartebeest, Grant's gazelle and giraffe. 
There are also large herds of buffalo, limited numbers of elephant - which should, however, increase with effective protection-and a very few rhinoceros (as far as is known at present not more than three or four pairs). Other species include defassa waterbuck, greater and lesser kudu, oribi, klipspringer, lion, leopard, cheetah and hunting dog, apart from the ubiquitous bushbuck, warthog and duiker.

\section{The Swamplands}

Beyond the Omo a massive spur of the Ethiopian plateau juts southwestwards to the Sudan border, forming both a watershed and an ecological barrier between the Lake Rudolf basin to the south-east and the Nile system with its swamps and high grass savannas to the west and north. The Gambella enclave, to the north of this divide, is a block of Ethiopian territory extending westwards into the Sudan. With its extensive swamps, flood plains and tracts of Terminalia woodland threaded by three major rivers (the Akobo, Ghilo and Baro, all tributaries of the Sobat) it is perhaps the richest game area in all Ethiopia.

The oryx, gazelle, gerenuk, lesser kudu and dikdik typical of the drier areas of the south and east do not occur, though Mongalla gazelle have been doubtfully reported from the lower Akobo River. In their place are swamp and savanna-dwelling species such as the Nile lechwe (Kobus megaceros), white-eared kob (K. kob leucotis), roan antelope and bohor reedbuck, while primates include the patas monkey (Erythrocebus patas), another typical savanna species. Similarly the reticulated giraffe of the south is here replaced by the Nubian giraffe of the Sudan. Other species common to both ecological zones are also found, including elephant, buffalo, tiang, Lelwel hartebeest, defassa waterbuck, oribi, lion and leopard (but not cheetah). Elephant and buffalo are certainly more abundant here than in any other area of Ethiopia, while roan are also unusually common. Certain species such as tiang and white-eared kob are subject to extensive seasonal movements - often in herds of many thousands - between Ethiopia and the Sudan; a subject requiring close study and possible joint protective measures by the two countries concerned.

Further north buffalo, elephant, roan, Lelwel hartebeest, giant forest hog, waterbuck, hippo and bohor reedbuck are found in Wollega Province, while black rhino have also been doubtfully reported. The tora hartebeest (Alcelaphus buselaphus tora), which is similar in general appearance to Swayne's hartebeest, replaces the Lelwel in the region of the Blue Nile. Beyond the Nile the country becomes progressively more arid, with the reappearance of gazelle, including Soemmering and red-fronted (Gazella rufifrons), on the Sudan side of the border, with Nubian ibex and dorcas gazelle occurring in the area of the Red Sea Hills, at the northern apex of the Ethiopian triangle. The northern limit of the range of elephant in Ethiopia is the Gash River in Eritrea $\left(15^{\circ} 10^{\prime} \mathrm{N}, 36^{\circ} 20^{\prime} \mathrm{E}\right)$ where a small isolated population still survives, and where it is hoped to establish a game reserve for the protection both of the elephant and other wildlife of the area. Nubian wild ass (Equus asinus africanus) were reliably reported in 1967 from the region of the Barca River, in western Eritrea, but their status in this area is as yet unknown. 
This general if necessarily somewhat superficial account of the distribution of the larger mammals would not be complete without some mention of the country's abundant and varied bird-life, which though it includes many species common to eastern Africa, also numbers others unique to Ethiopia, such as the blue-winged goose, thick-billed raven, wattled ibis, Abyssinian longclaw, white-collared pigeon and yellow-fronted parrot. Other interesting non-endemic species include the lammergeier, which is extraordinarily abundant in the highlands, the chough, which occurs in the Simien and Bale Mountains (where it reaches the southern limit of its range), the wattled crane and the ground-scraper thrush, both of which species exhibit a surprising gap in their distribution between Ethiopia and southern Tanzania. On certain of the inland waters, particularly the Rift Valley lakes, the great concentrations of pelicans, flamingos, ducks, geese and small waders present a memorable spectacle which could be a great attraction to tourists, and which it is intended to include in future plans for the development of conservation areas.

\section{Awash National Park}

At the present time wildlife conservation in Ethiopia is still very much in its infancy. As the result of recommendations of a UNESCO mission (Brown and Grimwood) which visited the country in 1964-65 a Wildlife Conservation Department was established some three years ago, and five expatriate game wardens have since been appointed to assist in the establishment of national parks and reserves and in the training of Ethiopian staff.

Greatest progress has so far been achieved in the development of the proposed Awash National Park, which is located some 130 miles east of Addis Ababa, between the foothills of the plateau and the western edge of the Danakil country, at an average elevation of about 3,000 feet. Approximately 250 square miles in area, it consists for the most part of open plains, short grass savanna and thornscrub, dominated by Mount Fantale, a spectacular dormant volcano rising to a height of over 6,000 feet. The fauna of the area includes large numbers of beisa oryx and Soemmering's gazelle, also greater and lesser kudu, Grévy's zebra, hippo, mountain reedbuck, bushbuck, dikdik, lion, leopard, cheetah and others, while over 400 different species of birds have so far been recorded. Other scenic attractions of the area, apart from Mount Fantale with its associated ash cones and lava flows, are the Awash River itself, its impressive falls and the deep gorge which forms the southern boundary of the proposed Park, and an extensive area of hot springs, fringed with doum palms (Hyphaene coriacea), the haunt of hippo and a wide variety of aquatic and other birds.

One of the greatest initial problems in developing Awash as a park was the large number of Danakil, Kurao and other nomadic tribesmen, with their great herds of camels, cattle, sheep and goats, who roamed the area and were causing rapid deterioration in the vegetation cover through overgrazing and trampling. However, after two years of patient and often dangerous work by the Warden and local government officials, both people and livestock have now been successfully moved and resettled 
elsewhere. A park headquarters with an airfield and tented camp for visitors has been established at Awash Falls, game guards posts have been constructed at various strategic points, and some 90 miles of roads and tracks opened up. With the arrival shortly of a substantial quantity of Russian roadmaking equipment, supplied by the USSR through FAO, the existing tracks will be improved and others opened. Already in de facto existence, it is hoped that Awash will soon be legally established and officially opened by the Emperor as Ethiopia's first national park.

Elsewhere work has been started on the proposed Simien Mountains Park near Gondar, which apart from providing protection for the rare walia ibex and other wildlife of the area should, by virtue of its fantastic scenery alone, which rivals that of the Grand Canyon in Arizona, prove a valuable addition to Ethiopia's many varied tourist attractions. A park is also planned in the Bale Mountains for the protection of the mountain nyala, and will be started as soon as the necessary staff and funds are available, while it is also hoped to set up a number of game reserves, sanctuaries and controlled hunting areas in other parts of the country.

It is certainly encouraging that a start has at last been made in the field of wildlife conservation in Ethiopia, but it is only a small beginning and a great deal has yet to be done both in the development of national parks and other conservation areas, in the introduction of effective protection of wildlife elsewhere against widespread poaching and destruction of the habitat, and also in ecological surveys to provide the necessary data on which to base management plans. One of the most urgent needs is for introduction of the up-to-date conservation legislation which has already been drafted and now only awaits the ministerial approval which it is hoped will be given in the near future. However, Ethiopia is a developing country with many calls on its limited financial resources, and outside assistance will therefore be essential if the limited conservation measures already introduced are to be further extended and made fully effective.

\section{REFERENCES}

BROWN, L. H., 1965, Conservation of Nature and Natural Resources in Ethiopia. UNESCO Report.

BROWN, L. H., 1965, Ethiopian Episode. Country Life, London.

BROWN, L. H. 1966, Mobil Handbook of Conservation in Ethiopia. Ethiopian Tourist Organisation, Addis Ababa.

FUNAIOLI, U. and SIMONETTA, A. M., 1966, The Mammalian Fauna of the Somali Republic: Status and Conservation Problems. Monitore Zoologico Italiano, Florence.

HUXLEY, J. et al., 1963, The Conservation of Nature and Natural Resources in Ethiopia. UNESCO Report, Paris. Summarised in Oryx, VII, August 5th, 1964.

MAYDON, H. C., 1925, Simien, its Heights and Abysses. Witherby, London.

SWAYNE, H. G. C., 1900, Seventeen Trips through Somaliland. London.

Von ROSEN, B., 1953, Game Animals of Ethiopia. Swedish-Ethiopian Co., Addis Ababa.

Von WOLFF, J., Freiherr, 1955, Mammals of Ethiopia and Principal Reptiles. Rhodesian Litho Ltd., Salisbury. 


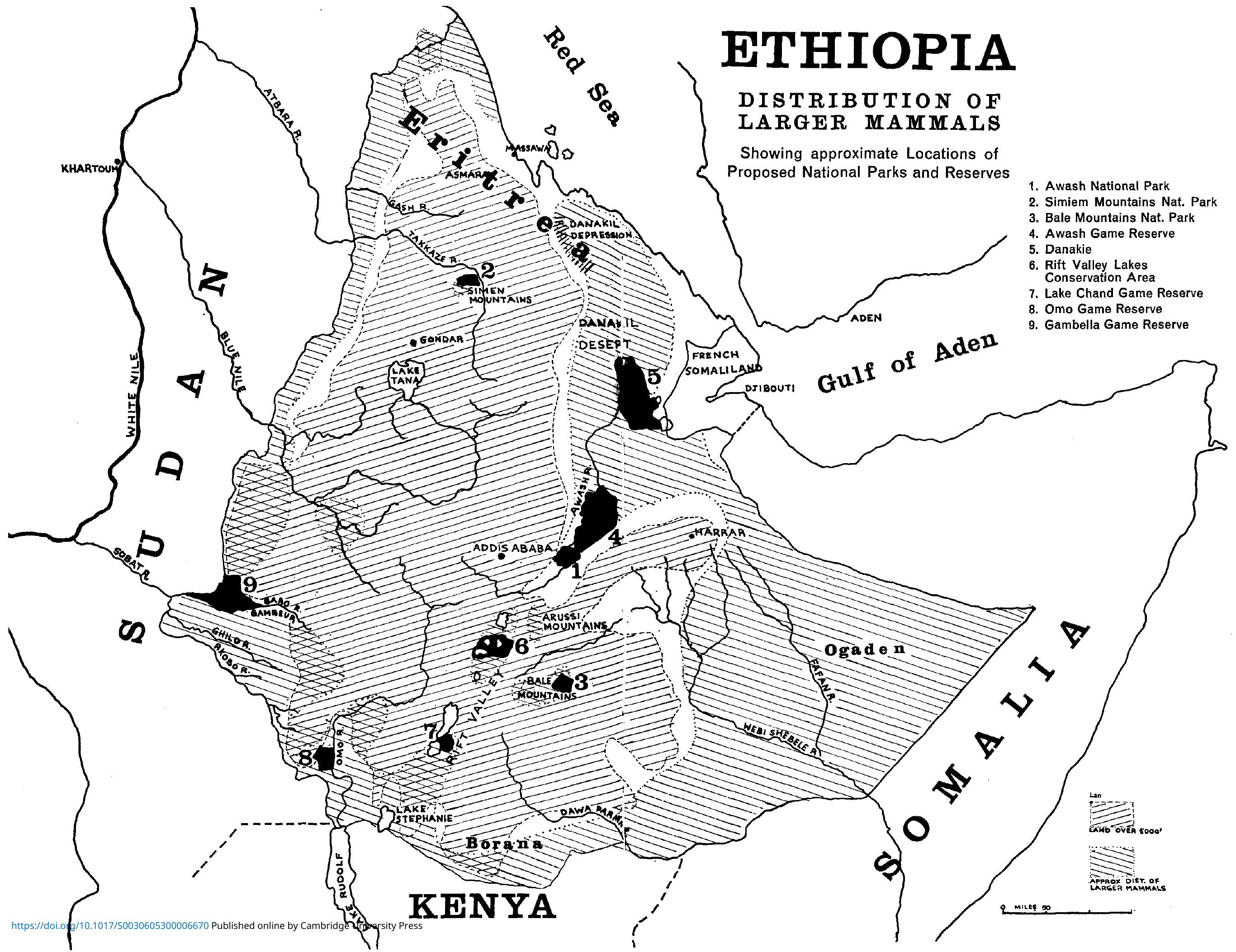

